\title{
Diagnostic value of pituitary volume in girls with precocious puberty
}

\author{
Su Wu ${ }^{1+}$, Yan Yang ${ }^{2 \dagger}$, Yujiao Wang ${ }^{1}$, Qianqi Liu', Ziyang Zhu ${ }^{1 *}$ (D) and Wei Gu ${ }^{1 *}$
}

\begin{abstract}
Background: To date, the gonadotropin-releasing hormone (GnRH) stimulation test is still the gold standard for precocious puberty (PP) diagnosis. However, it has many disadvantages, including low sensitivity, high cost, and invasive operation. This study aims to evaluate whether magnetic resonance imaging (MRI)-derived variables, including pituitary volume (PV), could be used as diagnostic factors for PP in girls, providing a non-invasive diagnostic approach for PP.
\end{abstract}

Methods: A total of 288 young female patients who presented to the Clinic of Pediatric Endocrinology for evaluation of PP from January 2015 to December 2017 were enrolled. The sample included 90 girls diagnosed with premature thelarche (PT), 133 girls determined as idiopathic central precocious puberty (ICPP), 35 early pubertal girls, and 30 normal girls. All patients received pituitary MRI examinations.

Results: The largest PV and pituitary height were shown in the ICPP and pubertal groups, followed by the PT group. The receiver operating characteristic (ROC) curve analysis showed that PV is a predictive marker for ICPP, with a sensitivity of $54.10 \%$ and a specificity of $72.20 \%$ at the cutoff value of $196.01 \mathrm{~mm}^{3}$. By univariate analysis, PV was positively associated with peak luteinizing hormone (LH), LH/follicle-stimulating hormone (FSH), age, bone age, and body mass index (BMI) (all $P<0.05)$. However, bone age and peak $L H$ were the only significant predictors of PV as demonstrated by the stepwise multivariate regression analysis (Model: $\mathrm{PV}=9.431{ }^{*}$ bone age $+1.230 *$ peak LH + 92.625 $\left.\left[P=0.000, R^{2}=0.159\right]\right)$.

Conclusions: The PV in the ICPP group was significantly higher than in PT and control groups, but there was no reliable cutoff value to distinguish ICPP from PT. Pituitary MRI should be combined with clinical and laboratory tests to improve the diagnostic value of PV for PP.

Keywords: Diagnosis, Precocious puberty, Puberty, Pituitary, MRl, Pituitary volume

\section{Background}

Precocious puberty (PP) is defined as the development of secondary sexual characteristics before the age of 9 years for boys and 8 years for girls $[1,2]$. The prevalence of PP in girls is approximately ten times higher than in boys, with the estimated register-based population

\footnotetext{
*Correspondence: uncombed_zzy@163.com; guwei154@163.com

'Su Wu and Yan Yang contributed equally to this work.

'Department of Endocrinology, Children's Hospital of Nanjing Medical University, Nanjing 210000, China

Full list of author information is available at the end of the article
}

prevalence of below $0.05 \%$ in boys and approximately $0.2 \%$ in girls [3].

Central precocious puberty (CPP) or gonadotropindependent precocious puberty results from early activation of the hypothalamic-pituitary-gonadal axis (HPGA). Mutations in the kisspeptin system, including makorin RING finger protein 3 (MKRN3) and delta-like1homologue (DLK1), have been identified in sporadic and familial cases of CPP. CPP may be either idiopathic or associated with abnormalities of the central nervous system (CNS), such as hamartomas and tumors. In girls, the prevalence of idiopathic central precocious puberty (ICPP) is from 80 to $90 \%$. In contrast,

C The Author(s). 2020 Open Access This article is licensed under a Creative Commons Attribution 4.0 International License, which permits use, sharing, adaptation, distribution and reproduction in any medium or format, as long as you give appropriate credit to the original author(s) and the source, provide a link to the Creative Commons licence, and indicate if changes were made. The images or other third party material in this article are included in the article's Creative Commons licence, unless indicated otherwise in a credit line to the material. If material is not included in the article's Creative Commons licence and your intended use is not permitted by statutory regulation or exceeds the permitted use, you will need to obtain permission directly from the copyright holder. To view a copy of this licence, visit http://creativecommons.org/licenses/by/4.0/ The Creative Commons Public Domain Dedication waiver (http://creativecommons.org/publicdomain/zero/1.0/) applies to the data made available in this article, unless otherwise stated in a credit line to the data. 
incomplete precocious puberty (IPP) develops when a secondary sexual characteristic appears, including the development of breasts and pubic hair without any hormonal changes in the HPGA. Representative types of IPP include isolated premature thelarche (PT), wherein the breasts develop, and premature adrenarche, wherein pubic and armpit hairs appear $[4,5]$. CPP eventually affects the physical growth of the child with a number of adverse effects $[6,7]$. Therefore, it is of great significance to distinguish CPP from common variants of $\mathrm{PP}$.

The gold standard for verifying HPG activity is the response of gonadotropin to a gonadotropin-releasing hormone $(\mathrm{GnRH})$ stimulation. To date, the GnRH stimulation test is still the gold standard for PP diagnosis [6, 8]. Although this test is highly specific, it has many disadvantages, such as low sensitivity, high cost, invasive operation, risk of local reaction, and unavailability of GnRH in some centers [9]. Therefore, the exploration of non-invasive diagnostic methods for CPP is urgent in the clinic.

Magnetic resonance imaging (MRI) is the currently preferred technique to image the pituitary gland and also performed in many tertiary care centers to rule out brain abnormalities for girls diagnosed with CPP $[10,11]$. Since the pituitary gland enlarges at puberty, it tends to be slightly larger in height for girls $(10 \mathrm{~mm})$ than for boys $(8 \mathrm{~mm})$. Previous studies have shown that the height of the pituitary gland in the CPP group is higher than in the normal group $[12,13]$. The pituitary volume (PV) has also been found to be increased with age and associated with hormonal levels [14]. However, this finding may be compromised since the incidence of these cases is rare. Besides, the relationship between PV and hormones, and the role of PV in the diagnosis of PP are still unclear.

Therefore, in this study, we aimed to evaluate the pituitary gland by MRI in PP children compared with agematched control subjects. Meanwhile, we also investigated the impacts of MRI-derived variables on the diagnosis of PP.

\section{Methods}

\section{Subjects}

The research protocol of this retrospective study was approved by the Ethics Committee of the Children's Hospital of Nanjing Medical University. The written informed consent for all the subjects to participate in this study was provided by their parents, guardians, or next of kin.

The subjects of this study were 258 young female patients who presented to the Clinic of Pediatric Endocrinology of children's hospital of Nanjing medical university for evaluation of PP from January 2015 to December 2017. The patients associated with endocrine disorders, previous hormonal therapies, malformations, neurofibromatosis, or congenital adrenal hyperplasia were not included in this study. Finally, among enrolled 258 girls, 133 girls (mean age 6.99 years, range 2.0-8.5) were diagnosed with ICPP, 90 girls (mean age 6.88 years, range 2.5-8.5) were determined to have PT, whereas 35 girls were classified as having early puberty in clinical practice.

\section{Detection indicators}

The patient's age, height, weight, bone age, and laboratory testing results were collected. Body mass index (BMI) was calculated by dividing weight in kilograms by height in meters squared.

All the subjects underwent brain MRI with a detailed examination of the pituitary gland at diagnosis. The control group included 30 age-matched girls (mean age 6.90 years, range 5.0-8.0) who underwent MRI for the examination of headaches or seizures rather than breast development.

\section{The clinical diagnostic basis for the ICPP}

The diagnosis of ICPP must conform to the diagnosis of $\mathrm{CPP}$, and the pituitary MRI examination is normal. The diagnosis of CPP needs to be consistent with [15]: (1) The emergence of secondary sexual characteristics: girls 8 years old, boys 9 years old before the development. The first manifestation was the appearance of breast nodules in girls and increased testicular volume in boys. (2) Linear growth acceleration: The annual growth rate is higher than normal children. (3) Bone age ahead: advanced bone age is 1 year or more than the actual age. (4) Gonadal enlargement: Pelvic ultrasound shows that the uterus and ovaries of the girl increase in volume, and multiple follicles with a diameter of $>4 \mathrm{~mm}$ are seen in the ovary; the testicular volume of the boy is $>4 \mathrm{ml}$. (5) HPGA function starts, serum gonadotropin and sex hormone reach puberty level.

In this study, the diagnosis of CPP was based on the gonadotropin response to a GnRH stimulation test [16]. Patients with a peak luteinizing hormone (LH) value of $>5 \mathrm{IU} / \mathrm{L}$ in the $\mathrm{GnRH}$ stimulation test were classified as having CPP, whereas those with a peak $\mathrm{LH}$ of $<5 \mathrm{IU} / \mathrm{L}$ were classified as having premature thelarche (PT). Notably, the GnRH stimulation test was not performed in the control group, because the $\mathrm{GnRH}$ stimulation test is an invasive test and it is meaningless for the undeveloped children.

\section{The clinical diagnostic basis for the PT}

The diagnostic criteria of PT are as follows [15]: accompanied by breast development, and is not accompanied by other signs of sexual development, no growth acceleration and early bone development, and without vaginal bleeding. The HPGA function was not activated and the 
basic values of serum estradiol and follicle-stimulating hormone (FSH) were often slightly increased.

\section{The clinical diagnostic basis for the early puberty}

Diagnostic criteria for early puberty are as follows [17]: usually, the first 1-2 years of puberty and our study selects girls who have breast development after 8 years of age and the HPGA axis starts, just entering puberty.

\section{MRI}

MRI was performed on a 1.5 -T MRI (1.5 T MAGN ETOM Symphony, Siemens Healthcare, Erlangen, Germany). The PV was calculated by measuring the length $(\mathrm{L})$, height $(\mathrm{H})$, and width $(\mathrm{W})$ in millimeters of the pituitary. Length and height were determined on the midline sagittal thin section from the posterior wall to the anterior wall. The width was measured on the thin coronal section from anterior to the entrance of the pituitary stalk. Volumes were determined using the ellipsoid formula $L^{*} \mathrm{H}^{*} \mathrm{~W} / 2[18,19]$. The pituitary shape was visually assessed using the Elster's grade [20], based on the contour of the gland's superior surface in the midsagittal projection (grade $1=$ marked concavity, grade $2=$ mild concavity, grade $3=$ flat, grade $4=$ mild convexity, grade $5=$ marked convexity). In this study, we classified the pituitary shape into 3 grades: concave (grade 1 and grade 2), flat, and convex (grade 4 and grade 5).

\section{GnRH stimulation testing}

Regarding the GnRH stimulation test, $\mathrm{LH}$ and $\mathrm{FSH}$ levels were determined at $0,30,60$, and $90 \mathrm{~min}$ after the intravenous injection of $\mathrm{GnRH}(2-3 \mu \mathrm{g} / \mathrm{kg}, \leq 100 \mu \mathrm{g})$ on Roche E602 using LH electrochemiluminescence detection kit and FSH electrochemiluminescence detection kit in accordance with the kit protocols.

\section{Statistical analysis}

Statistical analysis was performed using SPSS software, version 19.0 (SPSS Inc., Chicago). The data were shown as the mean \pm standard deviation (SD). Differences among the different groups were analyzed by one-way analysis of variance (ANOVA), followed by LSD test. Statistical significance was determined as $P<0.05$.

For evaluation of the diagnostic value of the PV, receiver operating characteristic (ROC) curve analysis was performed, in which ICPP and PT groups were the dependent variables, whereas the pituitary height, length, width, and volume were the independent variables. The optimal cutoff values were evaluated by using the Youden index (J) [21], which is defined as $J=$ maximum (sensitivity + specificity -1 ).

Univariate analysis was performed using the Pearson correlation coefficient for continuous variables. Stepwise multivariate regression analysis was performed using peak LH, peak FSH, LH/FSH, age, bone age, and BMI as independent variables and PV as the dependent variable.

\section{Results \\ Comparison of clinical characteristics among PT, ICPP, and pubertal groups}

As shown in Table 1, BMI was not significantly different among PT, ICPP, and pubertal groups $(P=0.782)$. Compared with the pubertal group, the peak $\mathrm{LH}$, peak FSH, the ratio of peak LH to peak FSH (LH/FSH), bone age, height, and weight were significantly lower in PT group (all $P<0.05$ ); the peak $\mathrm{LH}$, bone age, and height were also significantly lower while the advancement of bone age over chronological age $(\Delta$ age $)$ was significantly higher in ICPP group (all $P<0.05$ ).

Furthermore, the peak LH, peak FSH, LH/FSH, bone age, and $\triangle$ age were significantly higher in the ICPP group than the PT group (all $P<0.05$ ).

\section{Comparison of pituitary MRI results between control, PT, ICPP, and pubertal groups}

The MRI results showed that the pituitary length, height, and PV of the ICPP group were significantly higher than those of the PT group (all $P<0.05$ ), but they were not significantly different between PT group and control group. However, the pituitary width in the PT group was significantly higher than in the control group $(P<0.05)$. Analysis of the pituitary shape demonstrated that the proportion of convexity was increased gradually in the four groups, $6.7 \%$ for the control group, $12.2 \%$ for PT, $18.8 \%$ for ICPP, and $28.6 \%$ for the pubertal group (Table 2). The representative MRI images for concave, flat, and convex were shown in Fig. 1.

Table 1 Comparison between groups for clinical characteristics

\begin{tabular}{lllll}
\hline & PT & ICPP & Pubertal & $P$ \\
\hline Number & 90 & 133 & 35 & \\
Peak LH & $3.09 \pm 1.27 \wedge \wedge \wedge$ & $16.27 \pm 11.98^{* * *}$ & $20.22 \pm 15.35 \#$ & 0.000 \\
Peak FSH & $11.75 \pm 4.85 \wedge$ & $17.21 \pm 8.50^{* * *}$ & $14.59 \pm 6.73$ & 0.000 \\
LH/FSH & $0.28 \pm 0.14 \wedge \wedge \wedge$ & $1.05 \pm 0.77^{* * *}$ & $1.38 \pm 0.98$ & 0.000 \\
Bone age $(\mathrm{yr})$ & $8.09 \pm 1.91 \wedge \wedge \wedge$ & $8.82 \pm 1.74^{* *}$ & $10.08 \pm 1.30 \# \#$ & 0.000 \\
$\Delta$ age $(\mathrm{yr})$ & $1.25 \pm 1.26$ & $1.83 \pm 1.31^{* *}$ & $1.20 \pm 1.28 \#$ & 0.001 \\
BMI $\left(\mathrm{kg} / \mathrm{m}^{2}\right)$ & $16.66 \pm 2.03$ & $16.49 \pm 2.22$ & $16.72 \pm 1.83$ & 0.782 \\
Height $(\mathrm{cm})$ & $126.95 \pm 9.35 \wedge$ & $129.40 \pm 9.70$ & $133.56 \pm 5.43 \#$ & 0.001 \\
Weight $(\mathrm{cm})$ & $27.12 \pm 5.75 \wedge$ & $27.86 \pm 6.10$ & $29.97 \pm 5.88$ & 0.051 \\
\hline
\end{tabular}

Data are expressed as the mean \pm SD

Data were analyzed by one-way ANOVA

Comparison between ICPP and PT, ${ }^{* *} P<0.01,{ }^{* * *} P<0.001$

Comparison between ICPP and pubertal group, \#P<0.05, \#\#\# $P<0.001$

Comparison between PT and pubertal group, $\wedge P<0.05, \wedge \wedge \wedge P<0.001$

PT: premature thelarche, ICPP: idiopathic central precocious puberty, LH: luteinizing hormone, $\mathrm{FSH}$ : follicle-stimulating hormone, $\triangle$ age: bone agechronological age, BMI: body mass index 
Table 2 Comparison between groups for magnetic resonance imaging measurements

\begin{tabular}{|c|c|c|c|c|c|}
\hline & Control & PT & ICPP & Pubertal & $P$ \\
\hline Number & 30 & 90 & 133 & 35 & \\
\hline Age (yr) & $6.90 \pm 0.96$ & $6.83 \pm 1.36 \wedge \wedge \wedge$ & $6.99 \pm 1.33 \# \# \#$ & $8.86 \pm 0.37$ & 0.000 \\
\hline Length (mm) & $5.12 \pm 1.14 \& \&$ & $5.43 \pm 0.89$ & $5.79 \pm 0.94^{* *}$ & $5.69 \pm 0.92$ & 0.001 \\
\hline Width (mm) & $11.53 \pm 1.35 \$ \& \&$ & $12.22 \pm 1.51$ & $12.49 \pm 1.52$ & $12.35 \pm 1.44$ & 0.016 \\
\hline Height (mm) & $5.04 \pm 0.77 \&$ & $5.09 \pm 1.12^{\wedge}$ & $5.53 \pm 1.34^{*}$ & $5.65 \pm 1.24$ & 0.014 \\
\hline $\mathrm{PV}\left(\mathrm{mm}^{3}\right)$ & $148.72 \pm 44.28 \& \& \&$ & $170.94 \pm 60.13 \wedge$ & $200.17 \pm 67.33^{* *}$ & $200.56 \pm 75.40$ & 0.000 \\
\hline \multicolumn{6}{|l|}{ Grade } \\
\hline concave & 2 & 16 & 27 & 7 & \\
\hline flat & 26 & 63 & 81 & 18 & \\
\hline convex & 2 & 11 & 25 & 10 & \\
\hline Convex\% & $6.7 \%$ & $12.2 \%$ & $18.8 \%$ & $28.6 \%$ & 0.059 \\
\hline
\end{tabular}

Data are expressed as the mean \pm SD

Measurement data were analyzed by one-way ANOVA and count data were assessed by the chi-square test. Comparison between control group and PT, $\$ P<0.05$ Comparison between control group and ICPP, \& $P<0.05, \& \& P<0.01, \& \& \& P<0.001$

Comparison between ICPP and PT, ${ }^{*} P<0.05,{ }^{* *} P<0.01$

Comparison between ICPP and pubertal group, \#\#\# $P<0.001$

Comparison between PT and pubertal group, $\wedge P<0.05, \wedge \wedge \wedge P<0.001$

PT: premature thelarche, ICPP: idiopathic central precocious puberty, PV: pituitary volume

\section{Analysis of the ROC curve}

The area under the curve with $95 \%$ confidence interval (CI) for each MRI parameter was 0.599 (0.524-0.674) for pituitary length, $0.606(0.532-0.680)$ for pituitary height, $0.541(0.464-0.619)$ for pituitary width, and 0.639 (0.566-0.713) for PV. Moreover, the pituitary length showed a sensitivity of $61.70 \%$ and a specificity of $55.60 \%$ at the cutoff value of $5.445 \mathrm{~mm}$. A sensitivity of $45.90 \%$ and a specificity of $75.60 \%$ at the cutoff value of $5.725 \mathrm{~mm}$ was observed in the pituitary height. A sensitivity of $95.50 \%$ and a specificity of $11.10 \%$ at a cutoff value of $10.25 \mathrm{~mm}$ was found in the pituitary width. The PV was a predictive marker for ICPP, with a sensitivity of $54.10 \%$ and a specificity of $72.20 \%$ at the cutoff value of $196.01 \mathrm{~mm}^{3}$ (Table 3, Fig. 2).

\section{Correlation between PV and clinical and laboratory findings}

According to univariate analysis, we found that PV was positively associated with peak $\mathrm{LH}, \mathrm{LH} / \mathrm{FSH}$, age, bone age, and BMI $(P=0.000, P=0.000, P=0.001, P=0.000$, and $P=0.001$, respectively) (Table 4 , Fig. 3). After stepwise multivariate regression analysis, the bone age and peak LH were the only significant predictors for PV with the model: $\mathrm{PV}=9.431 *$ bone age +1.230 * peak $\mathrm{LH}+$ $92.625\left(P=0.000, \mathrm{R}^{2}=0.159\right)$ (Table 5).

\section{Discussion}

In this study, we found that the peak LH, peak FSH, LH/ $\mathrm{FSH}$, bone age, and $\Delta$ age were significantly higher in the ICPP group than the PT group. The pituitary length, height, and PV of the ICPP group were also significantly higher than those of the PT group, as demonstrated by the MRI examination. The PV might be a predictive marker for ICPP, with a sensitivity of $54.10 \%$ and a specificity of $72.20 \%$ at the cutoff value of $196.01 \mathrm{~mm}^{3}$. According to univariate analysis, PV was positively associated with peak LH, LH/FSH, age, bone age, and BMI. However, after stepwise multivariate regression analysis, the bone age and peak LH were the only significant predictors for PV. Taken together, pituitary MRI should be

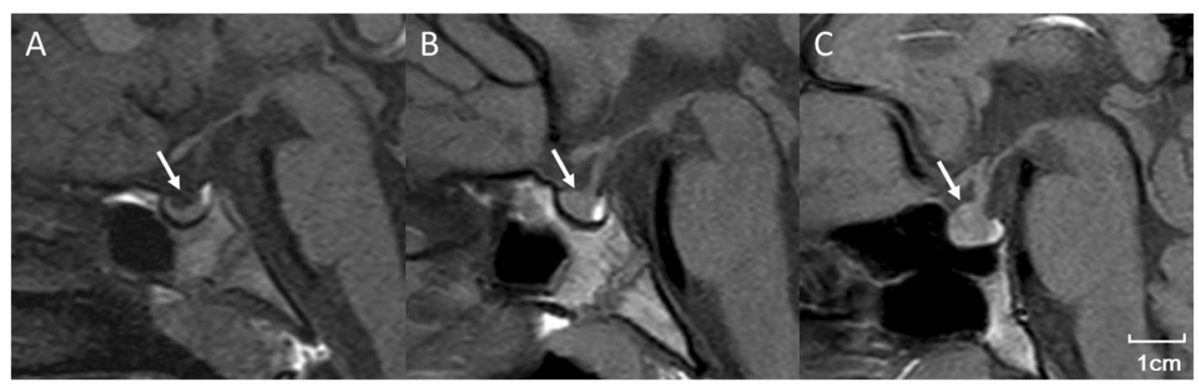

Fig. 1 Representative magnetic resonance imaging image for concave (a), flat (b), and convex (c) 
Table 3 Sensitivity, specificity, and Youden index J for several criterion values of pituitary volume

\begin{tabular}{llll}
\hline Criterion & Sensitivity(\%) & Specificity(\%) & Youden index J \\
\hline 188.37 & 57.90 & 66.70 & 0.246 \\
196.01 & 54.10 & 72.20 & 0.263 \\
205.70 & 44.40 & 80.00 & 0.244 \\
\hline
\end{tabular}

combined with clinical and laboratory tests to improve the diagnostic value of PV for PP.

It is difficult to distinguish ICPP and PT in the clinical diagnosis, but their differences in prognosis are extremely obvious. PT does not require treatment while ICPP has lasting adverse effects, such as short adult stature, and needs to be treated with long-acting luteinizing hormone-releasing hormone (LHRH) agonists $[9,10$, 22]. Therefore, it is of great significance to distinguish the two types of PP.

Due to the disadvantages of the GnRH stimulation test, MRI has become an alternative method to evaluate the pituitary gland and to be performed in many tertiary care centers to exclude brain abnormalities in girls diagnosed with CPP. In this study, to examine the effectiveness of MRI, we compared the MRI results among the PT, ICPP, pubertal, and control groups and found significant differences in the PV and pituitary height.
Patients in ICPP and pubertal groups had the largest PV and pituitary height, followed by patients with PT. In contrast, the control group had the smallest PV and pituitary height. Moreover, patients with larger pituitary glands had higher levels of LH and FSH.

CPP is accompanied by significant changes in the shape and size of the pituitary gland; patients with ICPP have a higher pituitary grade, height, and sagittal crosssectional area compared to age-matched normal subjects $[12,13,23]$. Besides, it has been shown that the PV of CPP children is higher, and the upper pituitary surface in CPP patients appears convex in a higher proportion [23]. However, no significant differences in the pituitary length, width, and volume were observed among the control, PT, and ICPP groups. In our study, the results demonstrated that PV and pituitary height in the ICPP group were higher than those in the control group. In addition, we first reported that the PV and pituitary height of the ICPP group were higher than those of the PT group and similar to those of the pubertal group. The ratio of convexity in the pituitary gland increased in the ICPP group compared to control and PT groups without significant difference.

The stepwise multivariate regression analysis in this study built a model $\left(R^{2}=0.159\right)$ that explained only $15.9 \%$ of the variability in PV, even though PV showed a

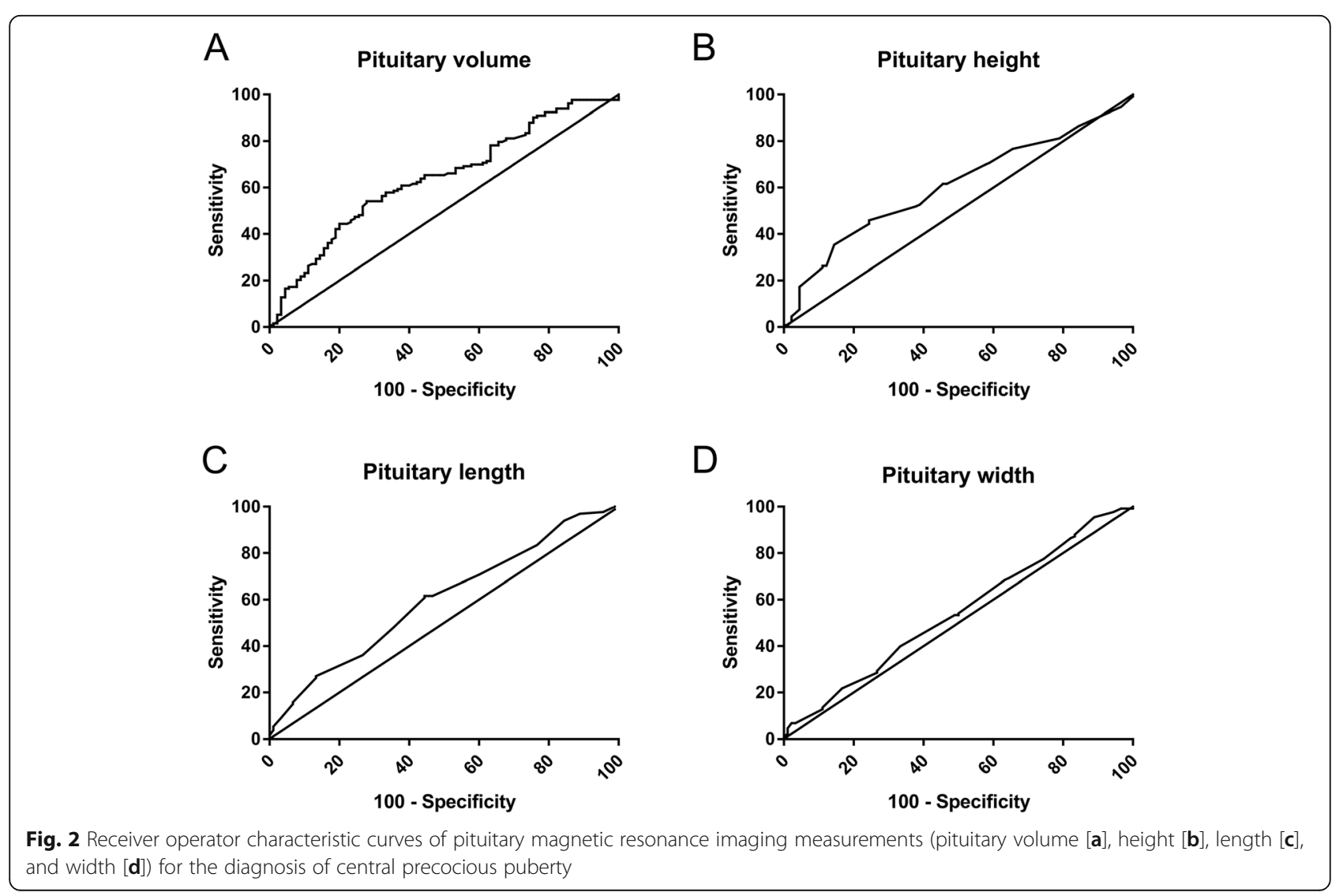



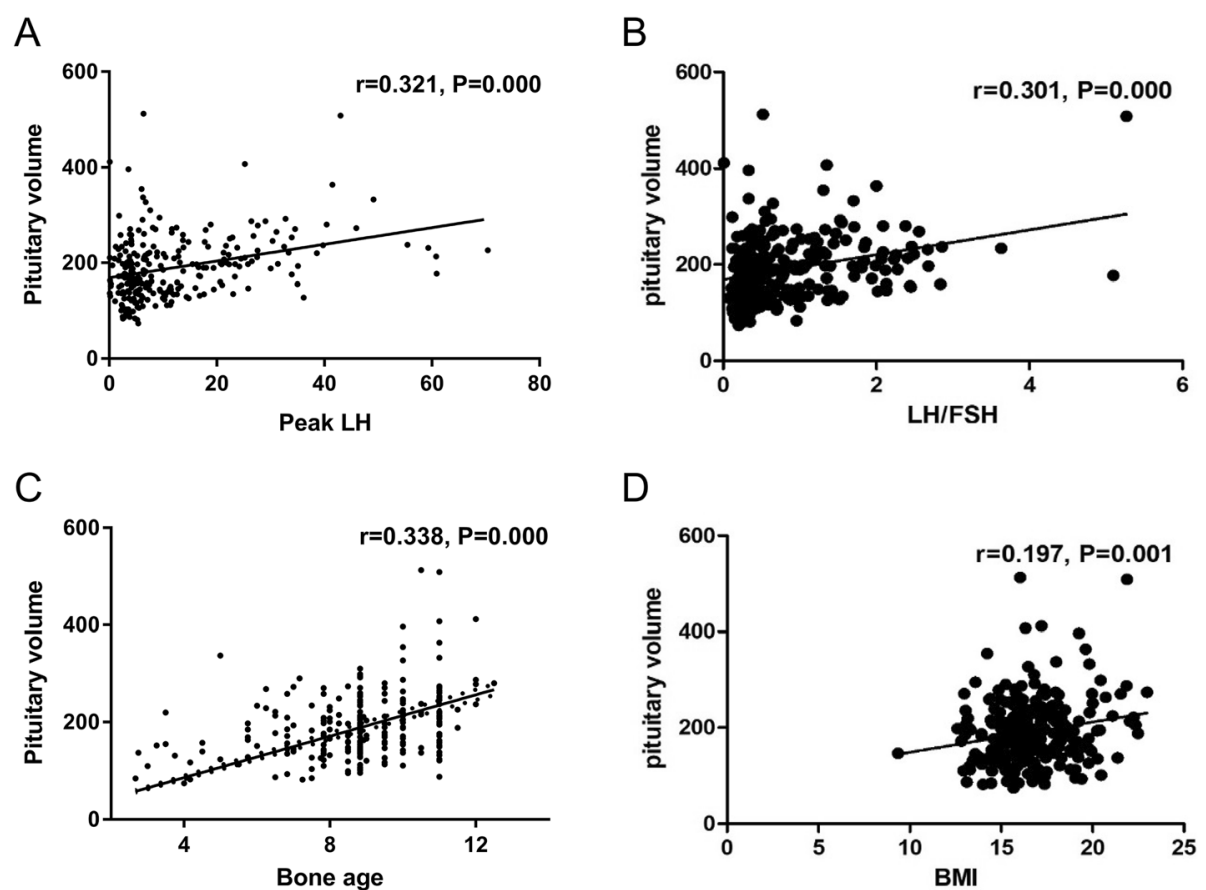

Fig. 3 Scatterplot for the peak luteinizing hormone (LH) [a], LH/ follicle-stimulating hormone (FSH) [b], bone age [c] , and BMI [d] according to pituitary volume

meaningful difference between the four groups. This phenomenon might result from the following reasons. Firstly, there was a lack of variables for generating a proper regression model, since many factors such as age, nutrition, race, sex, and the pubertal stage would influence PV [24-26]. Secondly, cells secreting gonadotrophs (LH and FSH) accounted for only $10 \%$ of the anterior pituitary cells and were distributed diffusely throughout the anterior lobe without effects on PV. Finally, the previous study showed that pituitary hypertrophy arose from the stimulation of growth-hormone-producing cells (somatotrophs) in the pituitary gland. The pituitary enlargement in puberty might also be correlated with the serum levels of somatomedin C [12].

Besides, our data indicate that a larger PV is correlated with a higher peak LH value, but not with the peak FSH

Table 4 Univariate analysis of the associations with pituitary volume

\begin{tabular}{lll}
\hline & $r$ & $P$ \\
\hline Peak LH & 0.321 & 0.000 \\
Peak FSH & 0.110 & 0.078 \\
LH/FSH & 0.302 & 0.000 \\
Age & 0.201 & 0.001 \\
Bone age & 0.338 & 0.000 \\
BMl & 0.197 & 0.001 \\
\hline LH luteinizing hormone, FSH follicle-stimulating hormone, BMI body & \\
mass index &
\end{tabular}

value. It has been shown that a larger PV is associated with a higher FSH production but is independent of pubertal development in normal subjects [14]. However, in this study, the positive association between LH and PV is linked to pubertal development. The previous study has demonstrated that the gradually elevated FSH had been already ongoing for several years prior to the onset of puberty [27]. Therefore, we propose that increased LH levels are associated with a larger pituitary gland during early puberty, whereas the association between peak FSH and PV is not obvious in the early adolescence.

We also conducted the univariate logistic regression analysis with each MRI parameter as an independent variable to evaluate the diagnostic value of pituitary MRI in CPP girls. The PV was a predictive marker for ICPP, with a sensitivity of $54.10 \%$ and a specificity of $72.20 \%$ at the cutoff value of $196.01 \mathrm{~mm}^{3}$. However, these results did show a reliable predictor. In general, the cutoff values obtained by ROC curves showed low sensitivity and specificity, even for the most potential predictor, PV.

This study had several limitations. Firstly, this was a retrospective study which might cause the loss of some clinical data. Secondly, we did not collect basal LH, basal FSH, E2, and Tanner stage. Thirdly, only one experienced radiologist performed all imaging studies. In addition, although the sample size of this study is larger than that of the previous studies $[12,13]$, the sample size is still relatively small considering the incidence of 
Table 5 Stepwise multivariate regression analysis of the associations with pituitary volume

\begin{tabular}{|c|c|c|c|c|c|}
\hline \multirow[t]{2}{*}{ Model } & \multicolumn{2}{|c|}{ Unstandardized Coefficients } & \multirow{2}{*}{$\begin{array}{l}\text { Standard } \\
\text { coefficient }\end{array}$} & \multirow[t]{2}{*}{$\mathrm{t}$} & \multirow[t]{2}{*}{$P$} \\
\hline & B & standard error & & & \\
\hline constant & 92.625 & 18.955 & & 4.887 & 0.000 \\
\hline Bone age & 9.431 & 2.239 & 0.260 & 4.212 & 0.000 \\
\hline Peak LH & 1.230 & 0.335 & 0.227 & 3.674 & 0.000 \\
\hline
\end{tabular}

All included variables are peak $\mathrm{LH}$, peak follicle-stimulating hormone (FSH), $\mathrm{LH}$ / FSH, body mass index, bone age. LH: luteinizing hormone

precocious puberty. The clinical manifestations of polycystic ovary syndrome (PCOS) patients mostly start in puberty and the main clinical features are particularly similar to physiological changes in puberty, such as insulin resistance $[28,29]$. CPP has been shown to be the first appearance of PCOS [30]. Our study did not include other comprehensive analyses such as ovarian color, Doppler ultrasound and other results, which are required to be assessed in the future.

\section{Conclusions}

The PV in the ICPP group was significantly higher than that in PT and control groups, but there was no reliable cutoff value to distinguish ICPP from PT. Pituitary MRI should be combined with clinical and laboratory tests to improve the diagnostic value of PV for PP, providing a non-invasive diagnostic method for PP.

\section{Abbreviations}

PP: Precocious puberty; CPP: Central precocious puberty; HPGA: Hypothalamic-pituitary-gonadal axis; MKRN3: Makorin RING finger protein 3; DLK1: Delta-like1homologue; CNS: Central nervous system; ICPP: Idiopathic central precocious puberty; IPP: Incomplete precocious puberty; PT: Premature thelarche; GnRH: Gonadotropin-releasing hormone; MRI: Magnetic resonance imaging; PV: Pituitary volume; BMI: Body Mass Index; LH: Luteinizing hormone; ET: Exaggerated thelarche; FSH: Folliclestimulating hormone; L : Length; H: Height; W: Width; SD: Standard deviation; ANOVA: Analysis of variance; ROC: Receiver operating characteristic; J: Youden index; Cl: Confidence interval; LHRH: Luteinizing hormone releasing hormone; PCOS: Polycystic ovary syndrome

\section{Acknowledgments}

Not applicable.

\section{Authors' contributions}

SW and YY designed the study, collected the data, and drafted the manuscript. YJW and QQL analyzed the data and helped to collect the data. ZYZ and WG conceived of the study and helped to draft the manuscript. All authors read and approved the final manuscript.

\section{Funding}

This work was supported by the key project of Nanjing Medical University Science and Technology Development Fund (No.2017NJMUZD063).

\section{Availability of data and materials}

The analyzed data sets generated during the study are available from the corresponding author on reasonable request.

\section{Ethics approval and consent to participate}

The research protocol of this study was approved by the Ethics Committee of the Children's Hospital of Nanjing Medical University. The written informed consent to participate for all the subjects in this study was provided by their parents, guardians, or next of kin.

\section{Consent for publication}

The written informed consent to publish for all the subjects in this study was provided by their parents, guardians, or next of kin.

\section{Competing interests}

There are no potential conflicts with any person or organization regarding this study.

\section{Author details}

'Department of Endocrinology, Children's Hospital of Nanjing Medical University, Nanjing 210000, China. 'Department of Radiology, Children's Hospital of Nanjing Medical University, Nanjing, China.

Received: 23 August 2019 Accepted: 9 August 2020

Published online: 05 September 2020

\section{References}

1. Partsch CJ, Heger S, Sippell WG. Management and outcome of central precocious puberty. Clin Endocrinol. 2002;56(2):129-48.

2. Brito VN, Latronico AC, Arnhold IJ, Mendonca BB. Update on the etiology, diagnosis and therapeutic management of sexual precocity. Arquivos brasileiros de endocrinologia e metabologia. 2008;52(1):18-31.

3. Teilmann G, Pedersen CB, Jensen TK, Skakkebaek NE, Juul A. Prevalence and incidence of precocious pubertal development in Denmark: an epidemiologic study based on national registries. Pediatrics. 2005;116(6): 1323-8.

4. Garibaldi LR, Aceto T, Weber C. The pattern of gonadotropin and estradiol secretion in exaggerated thelarche. Eur J Endocrinol. 1993;128(4):345-50.

5. Schwarz HP, Tschaeppeler H, Zuppinger K. Case report: unsustained central sexual precocity in four girls. Am J Med Sci. 1990;299(4):260-4.

6. Lee $S H$, Joo EY, Lee J-E, Jun Y-H, Kim M-Y. The diagnostic value of pelvic ultrasound in girls with central precocious puberty. Chonnam Med J. 2016; 52(1):70-4.

7. Willemsen R, Elleri D, Williams R, Ong K, Dunger D. Pros and cons of GnRHa treatment for early puberty in girls. Nat Rev Endocrinol. 2014;10(6):352-63.

8. Stanhope R, Brook CC. Thelarche variant: a new syndrome of precocious sexual maturation? Eur J Endocrinol. 1990;123(5):481-6.

9. Pescovitz $\mathrm{OH}$, Hench KD, Barnes KM, Loriaux DL, Cutler GB Jr. Premature thelarche and central precocious puberty: the relationship between clinical presentation and the gonadotropin response to luteinizing hormonereleasing hormone. J Clin Endocrinol Metab. 1988;67(3):474-9.

10. Cisternino M, Arrigo T, Pasquino A, Tinelli C, Antoniazzi F, Beduschi L, et al. Etiology and age incidence of precocious puberty in girls: a multicentric study. J Pediatr Endocrinol Metab. 2000;13(Suppl 1):695-701.

11. Kornreich L, Horev G, Blaser S, Daneman D, Kauli R, Grunebaum M. Central precocious puberty: evaluation by neuroimaging. Pediatr Radiol. 1995;25(1):7-11.

12. Sharafuddin MJ, Luisiri A, Garibaldi LR, Fulk DL, Klein JB, Gillespie KN, et al. MR imaging diagnosis of central precocious puberty: importance of changes in the shape and size of the pituitary gland. AJR Am J Roentgenol. 1994:162(5):1167-73.

13. Robben SG, Oostdijk W, Drop SL, Tanghe HL, Vielvoye GJ, Meradji M. Idiopathic isosexual central precocious puberty: magnetic resonance findings in 30 patients. Br J Radiol. 1995;68(805):34-8.

14. Peper JS, Brouwer RM, van Leeuwen M, Schnack HG, Boomsma DI, Kahn RS, et al. HPG-axis hormones during puberty: a study on the association with hypothalamic and pituitary volumes. Psychoneuroendocrinology. 2010;35(1): 133-40.

15. The Subspecialty Group of Endocinologic HaMD, The Society of Pediatrics, Chinese Medical Association, Editorial Board of Chinese Journal of Pediatrics. Consensus on the diagnosis and treatment of central precocious puberty (2015). Chinese J Pediatrics. 2015:53(6):412-8.

16. Neely EK, Hintz RL, Wilson DM, Lee PA, Gautier T, Argente J, et al. Normal ranges for immunochemiluminometric gonadotropin assays. J Pediatr. 1995; 127(1):40-6.

17. Mul D, Oostdijk W, Drop SL. Early puberty in girls. Best Pract Res Clin Endocrinol Metab. 2002;16(1):153-63. 
18. Kessler M, Tenner M, Frey M, Noto R. Pituitary volume in children with growth hormone deficiency, idiopathic short stature and controls. J Pediatr Endocrinol Metab. 2016;29(10):1195-200.

19. Chilton LA, Dorst JP, Garn SM. The volume of the Sella turcica in children: new standards. AJR Am J Roentgenol. 1983;140(4):797-801.

20. Elster AD, Chen MY, Williams DW 3rd, Key LL. Pituitary gland: MR imaging of physiologic hypertrophy in adolescence. Radiology. 1990;174(3 Pt 1):681-5.

21. Youden WJ. Index for rating diagnostic tests. Cancer. 1950;3(1):32-5.

22. Cacciari E, Fréjaville E, Cicognani A, Pirazzoli P, Frank G, Balsamo A, et al. How many cases of true precocious puberty in girls are idiopathic? J Pediatr. 1983;102(3):357-60.

23. Kao SC, Cook JS, Hansen JR, Simonson TM. MR imaging of the pituitary gland in central precocious puberty. Pediatr Radiol. 1992;22(7):481-4.

24. Tsunoda A, Okuda O, Sato K. MR height of the pituitary gland as a function of age and sex: especially physiological hypertrophy in adolescence and in climacterium. AJNR Am J Neuroradiol. 1997;18(3):551-4.

25. Denk CC, Onderoglu S, Ilgi S, Gurcan F. Height of normal pituitary gland on MRI: differences between age groups and sexes. Okajimas Folia Anat Jpn. 1999;76(2-3):81-7.

26. Takano K, Utsunomiya H, Ono H, Ohfu M, Okazaki M. Normal development of the pituitary gland: assessment with three-dimensional MR volumetry. AJNR Am J Neuroradiol. 1999:20(2):312-5.

27. Raivio T, Dunkel L. Inhibins in childhood and puberty. Best Pract Res Clin Endocrinol Metab. 2002;16(1):43-52.

28. Chiofalo B, Lagana AS, Palmara V, Granese R, Corrado G, Mancini E, et al. Fasting as possible complementary approach for polycystic ovary syndrome: Hope or hype? Med Hypotheses. 2017;105:1-3.

29. Lagana AS, Rossetti P, Sapia F, Chiofalo B, Buscema M, Valenti G, et al. Evidence-based and patient-oriented inositol treatment in polycystic ovary syndrome: changing the perspective of the disease. Int J Endocrinol Metab. 2017;15(1):e43695.

30. Escobar ME, Ropelato MG, Ballerini MG, Gryngarten MG, Rudaz MC, Veldhuis $J \mathrm{D}$, et al. Acceleration of luteinizing hormone pulse frequency in adolescent girls with a history of central precocious puberty with versus without hyperandrogenism. Horm Res. 2007:68(6):278-85.

\section{Publisher's Note}

Springer Nature remains neutral with regard to jurisdictional claims in published maps and institutional affiliations.

Ready to submit your research? Choose BMC and benefit from:

- fast, convenient online submission

- thorough peer review by experienced researchers in your field

- rapid publication on acceptance

- support for research data, including large and complex data types

- gold Open Access which fosters wider collaboration and increased citations

- maximum visibility for your research: over $100 \mathrm{M}$ website views per year

At $\mathrm{BMC}$, research is always in progress.

Learn more biomedcentral.com/submissions 